\title{
Efficacy and safety of long-term levamisole therapy in maintaining remission in steroid dependent nephrotic syndrome
}

\author{
H Dharmawardane ${ }^{1}$, S Abeyagunawardena ${ }^{2}$, U I Karunadasa ${ }^{3}$, A H H M Jayaweera ${ }^{3}$, \\ *A S Abeyagunawardena ${ }^{3}$
}

Sri Lanka Journal of Child Health, 2017; 46(4): 357-361

\begin{abstract}
Background: Levamisole (LEV) has been successfully used to maintain remission in steroid dependent nephrotic syndrome (SDNS). When compared to LEV, the costs of other immunosuppressive agents are more than tenfold. There is no uniform agreement on the duration of therapy and most authorities recommend 12 months of LEV.
\end{abstract}

Objective: To assess the efficacy and safety of a 5 year course of LEV in maintaining remission in SDNS in a single centre in Sri Lanka.

Method: Children with SDNS attending the nephrotic syndrome clinic at Teaching Hospital Peradeniya who were treated with alternate day LEV $2.5 \mathrm{mg} / \mathrm{kg}$ from 2004 to 2009 were studied. Children who have previously received immunosuppressive therapy other than prednisolone and LEV and children with renal histology other than minimal change disease were excluded. All patients had full blood counts and liver function tests performed every 3 months to monitor for any potential adverse effects.

Results: Of the 186 children studied, in 147 LEV was the final immunosuppressive therapy. LEV was discontinued in 2 children due to gastrointestinal intolerance and in 3 because of a vasculitic rash. Neither neutropenia nor liver dysfunction was a reason for discontinuation of LEV.

Conclusions: A 5 year course of LEV was effective and safe in maintaining remission in SDNS

\footnotetext{
${ }^{1}$ Nephrology Unit, Teaching Hospital Karapitiya, Galle, Sri Lanka, ${ }^{2}$ Outpatient Department, Teaching Hospital Peradeniya, Sri Lanka, ${ }^{3}$ Department of Paediatrics, University of Peradeniya, Sri Lanka

*Correspondence: asiriabey26@gmail.com
}

(Received on 14 March 2017: Accepted after revision on 17 April 2017)

The authors declare that there are no conflicts of interest

Personal funding was used for the project.

Open Access Article published under the Creative

Commons Attribution CC-BY (CC) (P) License
DOI: http://dx.doi.org/10.4038/sljch.v46i4.8384

(Keywords: Levamisole, immunosuppressive drugs, remission, safety, efficacy, nephrotic syndrome)

\section{Introduction}

According to the International Study of Kidney Disease in Children (ISKDC), majority of preadolescents with idiopathic nephrotic syndrome (NS) have minimal change nephropathy $(\mathrm{MCN})$ on renal biopsy ${ }^{1}$. Although corticosteroids are the first choice of treatment in NS with an initial response rate of nearly $90 \%$, relapses will follow in around $60-90 \%$ of patients who initially respond well. This complicates the treatment course for the clinician and also lowers the quality of life in patients ${ }^{2}$. NS ultimately becomes frequently relapsing or steroid dependent in about $20 \%$ to $60 \%$ of patients ${ }^{3}$.

Occurrence of 2 consecutive relapses during corticosteroid therapy or within 14 days of its cessation is known as steroid-dependent nephrotic syndrome (SDNS) ${ }^{4}$. The current practice is to treat relapses with $60 \mathrm{mg} / \mathrm{m}^{2}$ prednisolone on alternatedays until remission, followed by $40 \mathrm{mg} / \mathrm{m}^{2}$ every other day for 28 days. While relapses may be accompanied by complications such as sepsis, thrombosis, dyslipidaemia and malnutrition ${ }^{5}$, highdose prednisolone therapy may be associated with adverse effects such as avascular necrosis of the hip, hypertension, diabetes and behavioural disorders ${ }^{6}$. When encountering frequently relapsing or steroid dependent disease, treatment with long term alternate day prednisolone $(0.2-0.6 \mathrm{mg} / \mathrm{kg})$ is used to maintain remission. If patients continue to relapse on high dose alternate day prednisolone or develop unacceptable steroid related side effects, then steroid sparing therapy is considered ${ }^{5,7}$.

Levamisole (LEV), now widely known as an immunomodulatory agent, is used as a steroid sparing agent in SDNS. Normally it is administered at a dose of $2-2.5 \mathrm{mg} / \mathrm{kg}$ on alternate days for $12-24$ months ${ }^{4}$ and evidence of its safety beyond 24 months is lacking. Studies have shown that LEV reduces the frequency of relapses, prolongs remission and lowers cumulative steroid doses in SDNS patients, both as a first alternative for steroids and also following the use of cyclophosphamide or cyclosporine $^{8-12}$. 


\section{Objectives}

To assess the efficacy and safety of a 5 year course of LEV in maintaining remission in SDNS in a single centre in Sri Lanka.

\section{Method}

Teaching Hospital, Peradeniya conducts a weekly outpatient clinic dedicated to review patients with NS since 2002. Hence steroid resistant as well as steroid dependant patients are frequently referred from all parts of the country for further management. The clinical records including therapies, side effects, and results of investigations and complications of children with NS were electronically entered and regularly updated on a computerised database in accordance with the data protection act 1998 while maintaining patient confidentiality and the approval of the Research and Ethics Committee of the Faculty of Medicine, University of Peradeniya. This database was designed and maintained throughout with the supervision of the corresponding author.

Considering the toxicity of cyclophosphamide and the non-availability of cyclosporine A for children with steroid dependency, from 2004 patients received $0.2-0.6 \mathrm{mg} / \mathrm{kg}$ alternate-day prednisolone over 12 months as maintenance therapy and were prescribed LEV $2.5 / \mathrm{kg}$ on alternate-days for a period of 5 years in an attempt to reduce the steroid burden. Follow-up of these patients was done routinely on a monthly basis until the withdrawal of steroid therapy and thereafter 3 monthly follow-up visits were arranged. Follow up focused on the appearance of proteinuria, infections and potential side effects of LEV and steroid therapy. All patients had full blood counts, serum creatinine levels, and liver function tests (SGPT) performed 3 monthly to monitor for adverse effects. A patient-held health record was maintained for each patient including specifically designed nephrotic syndrome diary to record the results of daily urinary protein excretion and the medications taken. Parents were educated and trained to test urine protein excretion by using sulphosalicylic acid test.

The present study reviewed the outcome of children with SDNS attending the NS clinic at Teaching Hospital Peradeniya who were treated with alternate-day LEV $2.5 \mathrm{mg} / \mathrm{kg}$ for 5 years from 2004 to 2009. Children who had in the past received immunosuppressive therapy other than prednisolone and LEV and children with renal histology other than minimal change disease were excluded from the analysis.

An analysis was done on the mean steroid doses, occurrence of side effects, means of serum creatinine levels, haemoglobin $(\mathrm{Hb})$, neutrophil counts and liver function tests during the 5 year LEV course to assess its safety and efficacy. Neutropenia was defined as an absolute neutrophil count (ANC) below $1.5 \times 10^{9} / \mathrm{L}^{13}$. The data were analysed using descriptive statistics and nonparametric tests in SPSS software version 19.

\section{Results}

A total of 186 children were prescribed LEV during this 5 year period. In $147(76 \%)$ it was the final steroid sparing agent while 39 of them needed prescription of other immunosuppressive drugs to maintain remission. Levamisole was withdrawn in 5 (3.4\%) patients due to side effects. Gastrointestinal side effects were seen in $2(1.4 \%)$ patients, while LEV was stopped in 3 children due to vasculitic rash which recovered completely upon withdrawal (Figures 1a and 1b). All 3 patients who had involvement of the ear lobes and cheeks had a negative infection screen. All 5 patients in whom LEV was withdrawn subsequently needed other immunosuppressive therapy to maintain sustained remission.

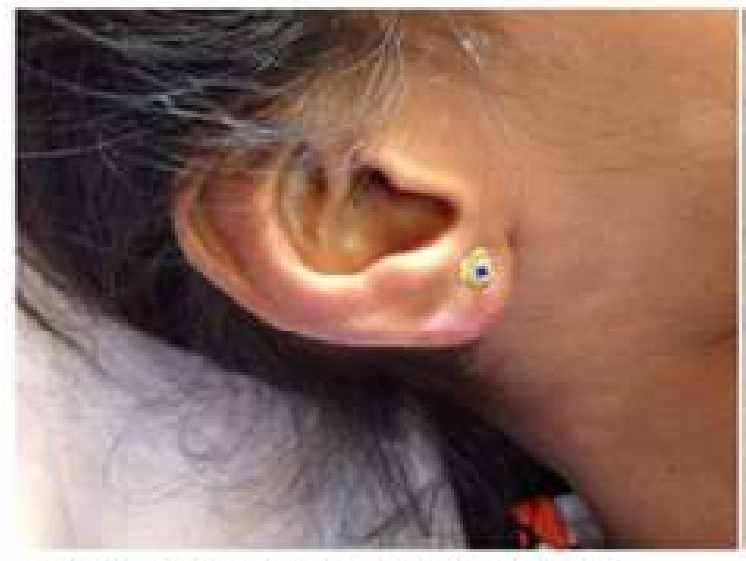

Figure 1a Vasculitic rash with ear lobe involvement

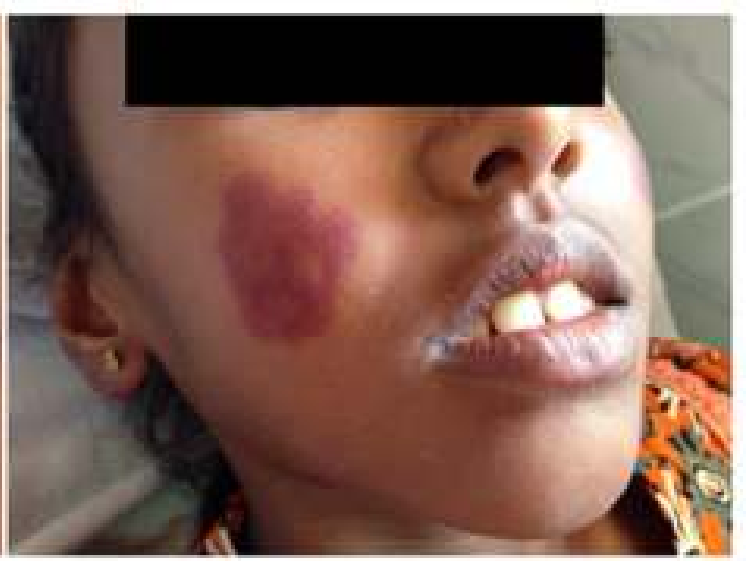

Figure 1b Vasculitic rash on the face 
Of the 147 children in whom LEV was continued for 5 years, $94(64 \%)$ were male and $53(36 \%)$ were female. The age at prescription ranged from $6.0-$ 14.2 years with a median age of 8.8 years. The mean number of relapses prior to the beginning of LEV course was 5.2. Minimum daily steroid dose was $0.2 \mathrm{mg} / \mathrm{kg}$ and maximum steroid dose was $0.6 \mathrm{mg} / \mathrm{kg}$ during this period, while the mean steroid dose was
$0.4 \mathrm{mg} / \mathrm{kg}$. Significant neutropenia was not observed during the study period. Regular liver function tests did not reveal any abnormalities. The results for blood, kidney and liver function tests are summarised in table 1 . At the end of 5 years of therapy all 147 patients were off steroid therapy and in sustained remission.

Table 1: Results of the screening tests done during the treatment period

\begin{tabular}{|l|c|c|}
\hline \multicolumn{1}{|c|}{ Blood, kidney and liver function test parameters } & Mean & Interquartile range (IQR) \\
\hline Neutrophil count $\left(10^{9} / \mathrm{L}\right)$ & 6.03 & $5.40-6.60$ \\
\hline Hb level $(\mathrm{g} / \mathrm{dL})$ & 11.82 & $10.90-12.70$ \\
\hline Serum creatinine $(\mu \mathrm{mol} / \mathrm{L})$ & 49.48 & $46.00-55.00$ \\
\hline SGPT level $(\mathrm{IU} / \mathrm{L})$ & 28.80 & $26.00-32.00$ \\
\hline
\end{tabular}

\section{Discussion}

The present study evaluates the efficacy and safety of LEV administered for a period of 60 months, to maintain remission in SDNS patients. Although LEV is the least toxic and least expensive among the steroid-sparing agents used for SDNS, it is neither approved nor widely used in Europe for NS. Difficulty in obtaining the drug in these countries may be one reason for this. A commentary by Davin and Merkus states that lack of good quality evidence for its effectiveness is another reason ${ }^{14}$.

Since most children with SDNS enter long-term remission with age, it is prudent to use a drug with minimal side effects to prevent relapses. Therefore the use of LEV instead of cytotoxic drugs to induce sustained remission is justified. The consensus statement published by British Association of Paediatric Nephrology in 1994 therefore suggested that LEV should be introduced as the first steroid sparing agent for patients when relapsing while receiving high dose alternate-day prednisolone ${ }^{7}$. However, subsequent to this, a large cohort study indicated that LEV was rather ineffective when used as the first steroid sparing agent when receiving high dose alternate day prednisolone ${ }^{12,15}$. The results of this study suggested that the steroid sparing effect of LEV is most evident when introduced at a later stage when the disease condition is more stable, and the patient is maintained with a lower dose of prednisolone. The present study revealed only a very low incidence of LEV-related side effects. However, the occurrence of necrotising vasculitic skin rash was dramatic, calling for urgent hospitalisation and withdrawal of the drug. In literature, this adverse effect has been reported in a very low number of patients ${ }^{16}$. All patients made a complete recovery upon withdrawal of the drug and supportive treatment. Therefore, when commencing on LEV, all patients should be warned about this potential side-effect and should be advised to stop the drug and report immediately. Neutropenia and liver toxicity have been reported in NS patients using $\mathrm{LEV}^{17,18}$. However, neutropenia, anaemia or liver toxicity were not observed in the present study. Furthermore, our study demonstrates that the side effect profile remains the same despite prolongation of therapy for 5 years.

Several studies have shown LEV to be efficacious in maintaining remission. In 1991 the study of the British Association for Paediatric Nephrology reported 3 months of sustained remission while this was 8-12 months in a study by Bagga et al in $1997^{19,20}$. The results of the present study are more encouraging than the previous research in the published literature in terms of the period of sustained remission. The number of patients to whom cyclophosphamide and cyclosporin A were ultimately prescribed due to the occurrence of frequent relapses while on the LEV therapy is also significantly lower, proving the efficacy of LEV in maintaining sustained remission.

\section{Conclusions}

A 5 year course of LEV was effective and safe in maintaining remission in SDNS

\section{References}

1. International Study of Kidney Disease in Children Nephrotic syndrome in children. Prediction of histopathology from clinical and laboratory characteristics at time of diagnosis. Kidney International 1978; 13:15965.

https://doi.org/10.1038/ki.1978.23

PMid: 713276

2. International Study of Kidney Disease in Children. The primary nephrotic syndrome in children. Identification of patients with minimal change nephrotic syndrome from initial response to prednisone. Pediatric Nephrology 1981; 98:561-4. 
3. Teeninga N, Kist-van Holthe JE, Nauta J. Extending prednisolone treatment does not reduce relapses in childhood nephrotic syndrome. Journal of the American Society of Nephrology 2012; 24:149-59. https://doi.org/10.1681/ASN.2012070646 PMid: 23274956 PMCid: PMC3537218

4. Bagga A. Revised guidelines for management of steroid-sensitive nephrotic syndrome. Indian Journal of Nephrology 2008; 18(1):31. https://doi.org/10.4103/0971-4065.41289 PMid: 20368921 PMCid: PMC2847730

5. Webb NJA. Epidemiology and general management of childhood idiopathic nephrotic syndrome. In: Molony D, Craig J, editors. Evidence-based Nephrology. Oxford, UK: Wiley-Blackwell; 2008. https://doi.org/10.1002/9781444303391.ch66

6. Hall AS, Thorley G, Houtman PN. The effects of corticosteroids on behaviour in children with nephrotic Nephrology 2003; 18:1220-3.

https://doi.org/10.1007/s00467-003-1295-x PMid: 14577022

7. Consensus statement on management and audit potential for steroid responsive nephrotic syndrome. Report of a workshop by the British Association for Paediatric Nephrology and Research Unit, Royal College of Physicians. Archives of Disease in Childhood 1994; 70(2):151-7.

https://doi.org/10.1136/adc.70.2.151

8. Rashid HU, Ahmed S, Fatima N, Khanam A. LEV in the treatment of steroid dependent or frequent relapsing nephrotic syndrome in children. Bangladesh Renal Journal 1996; 15:6-8.

9. Bagga A, Sharma A, Srivasta RN. LEV therapy in corticosteroid-dependent nephrotic syndrome. Pediatric Nephrology 1997; 11: 415-7.

https://doi.org/10.1007/s004670050307

PMid: 9260236

10. Tenbrock K, Müller-Berghaus J, Fuchshuber A, Michalk D, Querfeld U. Levamisole treatment in steroid-sensitive and steroid-resistant nephrotic syndrome. Pediatric Nephrology 1998; 12:459-62.

https://doi.org/10.1007/s004670050487

PMid: 9745868
11. Hafeez F, Ahmed T, Samina U. Levamisole in steroid dependent and frequently relapsing nephrotic syndrome. Journal of the College of Physicians and Surgeons-Pakistan 2006; 16(1):35-7.

PMid: 16441986

12. Abeyagunawardena A, Dillon M, Rees L, van't Hoff W, Trompeter R. The use of steroidsparing agents in steroid-sensitive nephrotic syndrome. Pediatric Nephrology 2003; 18(9):919-24.

https://doi.org/10.1007/s00467-003-1216-z PMid: 12883981

13. Newburger P, Dale D. Evaluation and Management of Patients with Isolated Neutropenia. Seminars in Hematology 2013; 50(3):198-206.

https://doi.org/10.1053/j.seminhematol.2013.0 6.010

PMid: 23953336 PMCid: PMC3748385

14. Davin J, Merkus M. Levamisole in steroidsensitive nephrotic syndrome of childhood: the lost paradise? Pediatric Nephrology 2004; 20(1):10-14. https://doi.org/10.1007/s00467-004-1615-9 PMid: 15378419

15. Neuhaus T, Fay J, Dillon M, Trompeter R, Barratt T. Alternative treatment to corticosteroids in steroid sensitive idiopathic nephrotic syndrome. Archives of Disease in Childhood 1994; 71(6):522-6.

https://doi.org/10.1136/adc.71.6.522

PMid: 7726612 PMCid: PMC1030089

16. Symoens J, Veys E, Mielants M, Pinals R. Adverse reactions to levamisole. Cancer Treatment Reports 1978; 62(11):1721-30. PMid: 365327

17. Sumegi V, Haszon I, Ivanyi B, Bereczki C, Papp F, Tori S. Long-term effects of levamisole treatment in childhood nephrotic syndrome. Pediatric Nephrology 2004; 19(12):1354-60. https://doi.org/10.1007/s00467-004-1608-8 PMid: 15517419

18. Bulugahapitiya D. Liver toxicity in a nephrotic patient treated with levamisole. Archives of Disease in Childhood 1997; 76(3): 289. https://doi.org/10.1136/adc.76.3.289 PMid: 9135277 PMCid: PMC1717095 
19. British Association for Pediatric Nephrology. Levamisole for corticosteroid-dependent nephrotic syndrome in childhood. Lancet 1991; 337:1555-7.

PMid: 1675705

20. Bagga A, Sharma A, Srivastiva RN. Levamisole therapy in corticosteroid-dependent nephrotic syndrome. Pediatric Nephrology 1997; 11:415-7.

https://doi.org/10.1007/s004670050307

PMid: 9260236 